\title{
Socioeconomic deprivation and provision of acute and long-term care after stroke: the South London Stroke Register cohort study
}

\author{
Ruoling Chen, ${ }^{1}$ Christopher McKevitt, ${ }^{1}$ Siobhan L Crichton, ${ }^{1}$ Anthony G Rudd, ${ }^{1,2}$ \\ Charles D A Wolfe ${ }^{1,2}$
}

\begin{abstract}
- Additional material is published online. To view please visit the journal (http:// dx.doi.org/10.1136/jnnp-2013306413).

${ }^{1}$ Division of Health and Social Care Research, King's College London, London, UK

${ }^{2}$ National Institute for Health Research Comprehensive Biomedical Research Centre, Guy's and St Thomas' NHS Foundation Trust and King's College London, London, UK
\end{abstract}

\section{Correspondence to} Dr Ruoling Chen, Division of Health and Social Care Research, King's College London, 7th Floor, Capita House, 42 Weston Street, London, SE1 30D, UK: ruoling.chen@kcl.ac.uk

The study was orally presented in XXI European Stroke Conference, Lisbon, Portugal, 22-25 May 2012

Received 26 July 2013 Revised 13 November 2013 Accepted 26 February 2014 Published Online First 14 April 2014

\section{ABSTRACT \\ Background and aims Socioeconomic deprivation (SED) is associated with increased mortality after stroke, however, its associations with stroke care remains uncertain. We assessed the SED impacts on acute and long-term stroke care, and examined their ethnic differences and secular trends. \\ Methods We used data from 4202 patients with first-ever stroke (mean age 70.1 years, $50.4 \%$ male, $20.4 \%$ black), collected by a population-based stroke register in South London, England from 1995 to 2010. Carstairs deprivation score was measured for each patient, taking the 1st as the least deprived and the 2 nd to 5 th quintiles as SED, and was related to 20 indicators of care in multivariate logistic regression models.}

Results Patients with SED had 29\% and 35\% statistically significant reductions in odds of being admitted to hospital and having swallow tests, respectively. The multivariate adjusted odds ratio (OR) for receiving five indicators of acute stroke care was $0.81(95 \% \mathrm{Cl} 0.72$ to 0.92$)$. It was 0.76 (0.58 to 0.99 ) in black patients and $0.82(0.71$ to 0.96$)$ in white patients; and 0.70 (0.58 to 0.84$)$ in patients with stroke occurring before 2001 and 0.89 (0.75 to 1.05) since 2001. SED was further associated with receipt of some stroke care during 5 years of follow-up, including atrial fibrillation medication $(0.63,0.48$ to $0.83)$, and in black patients physiotherapy and occupational therapy $(0.32,0.11$ to 0.92$)$.

Conclusions Stroke healthcare inequalities in England exist for some important indicators, although overall it has improved over time. The impact of SED may be stronger in black patients than in white patients. Further efforts are required to achieve stroke care equality.

\section{INTRODUCTION}

Stroke is the leading cause of adult disability and is the second highest cause of death in the world. ${ }^{1}$ Previous research has shown that people in low socioeconomic groups have a significantly increased risk of stroke. ${ }^{2}$ There is also substantial evidence for the existence of a socioeconomic gradient in recurrences and mortality. ${ }^{2-5}$ However, the reasons for these findings of poor prognosis of stroke among patients with socioeconomic deprivation (SED) are not well understood. Some but not all studies have shown an association of SED with poor provision of acute care after stroke. ${ }^{2}$ This uncertainty also holds true in high-income countries. ${ }^{5-9}$ Furthermore, the SED impact on longterm stroke care remains unclear. ${ }^{2} 6$ Although more people of minority ethnic populations live in Western countries and are more likely to experience socioeconomic disadvantage than their white counterparts, few studies have been done to investigate socioeconomic inequalities among ethnic minorities on accessing stroke care. While many governments have campaigned to reduce health inequality in stroke for decades, ${ }^{6} 1011$ little is known about whether the SED impact on access to stroke care has changed over time.

In this study we examined the association of SED with the provision of acute and long-term stroke care, using data from a population register covering an inner city multiethnic population in England. ${ }^{12}$ We further investigated secular trends and ethnic differences in the impact of SED.

\section{METHODS}

Patients and provision of stroke care data collection

The study population was derived from the South London Stroke Register (SLSR). ${ }^{12}{ }^{13}$ Its methodology has been fully described before. ${ }^{12} 1415$ In brief, the SLSR is an ongoing prospective population-based stroke register set up in January 1995, recording all first-ever strokes in patients of all ages living in 22 electoral wards in Lambeth and Southwark (total population at the 2001 census was 271817 ), inner city South London. ${ }^{13}{ }^{16}$ In this study, we included all data collected until 31 December 2010.

We identified patients using multiple sources of notification by specially trained study nurses and fieldworkers, from hospital and community surveillances for stroke. ${ }^{13} 16$ Patients or their relatives gave written informed consent to participate in the study. Patients' ethnicity was recorded by self definition of ethnic origin (2001 UK census question) stratified into white, black (black Caribbean, black African and black other) and other ethnic groups (South Asians (Indian, Pakistani, Bangladeshi), Chinese, other Asians, etc). According to patients' postcode of residence at the time of stroke, we calculated the Carstairs deprivation index score ${ }^{17}$ to measure baseline SED for each patient, as we did in previous studies. ${ }^{18} 19$ The Carstairs index is an area-based measure of SED derived from decennial census data, using levels of male unemployment, 
Table 1 Characteristics of patients with stroke across socioeconomic deprivation groups in SLSR of 1995-2010

\begin{tabular}{|c|c|c|c|c|c|}
\hline \multirow[b]{3}{*}{ Variable } & \multicolumn{4}{|c|}{ Socioeconomic deprivation (Carstairs score-quintile) } & \multirow[b]{3}{*}{ p Value } \\
\hline & \multicolumn{2}{|c|}{$\begin{array}{l}\text { Deprived (2nd-5th Q) } \\
\mathrm{N}=3361\end{array}$} & \multicolumn{2}{|c|}{$\begin{array}{l}\text { Least deprived (1st Q) } \\
\mathrm{N}=841\end{array}$} & \\
\hline & $\mathrm{n}$ & Per cent & n & Per cent & \\
\hline Age (years), median, IQR & \multicolumn{2}{|c|}{$72.6(61.5-81.1)$} & \multicolumn{2}{|c|}{$72.3(61.9-81.3)$} & 0.602 \\
\hline Male sex, $\mathrm{n}(\%)$ & 1707 & 50.8 & 410 & 48.9 & 0.539 \\
\hline \multicolumn{6}{|l|}{ Ethnicity, $\mathrm{n}(\%)^{*}$} \\
\hline White & 2417 & 71.9 & 581 & 69.1 & 0.019 \\
\hline Black & 655 & 19.5 & 202 & 24.0 & \\
\hline Other & 201 & 6.0 & 41 & 4.9 & \\
\hline Unknown & 88 & 2.6 & 17 & 2.0 & \\
\hline \multicolumn{6}{|l|}{ Year of stroke, n (\%) } \\
\hline 1995-1997 & 755 & 22.5 & 209 & 24.9 & 0.018 \\
\hline $1998-2000$ & 678 & 20.2 & 172 & 20.5 & \\
\hline $2001-2003$ & 660 & 19.6 & 155 & 18.4 & \\
\hline 2004-2006 & 574 & 17.1 & 168 & 20.0 & \\
\hline $2007-2010$ & 694 & 20.7 & 137 & 16.3 & \\
\hline \multicolumn{6}{|l|}{ Living conditions before stroke, $\mathrm{n}(\%)$} \\
\hline Alone in private accommodation & 1054 & 31.4 & 225 & 26.8 & 0.055 \\
\hline With others in private accommodation & 1568 & 46.7 & 420 & 49.9 & \\
\hline Nursing home or other & 671 & 20.0 & 182 & 21.6 & \\
\hline Unknown & 68 & 2.0 & 14 & 1.7 & \\
\hline \multicolumn{6}{|l|}{ BI prior to stroke, $\mathrm{n}(\%)$} \\
\hline 20, independent & 2490 & 74.1 & 622 & 74.0 & 0.695 \\
\hline 15-19, mild disability & 477 & 14.2 & 117 & 13.9 & \\
\hline $0-14$, moderate-severe disability & 224 & 6.7 & 55 & 6.5 & \\
\hline Unknown & 170 & 5.1 & 47 & 5.6 & \\
\hline \multicolumn{6}{|l|}{ Stroke subtype, n (\%) } \\
\hline Infarction & 2471 & 73.5 & 631 & 75.0 & 0.575 \\
\hline Primary intracerebral haemorrhage & 434 & 12.9 & 106 & 12.6 & \\
\hline Subarachnoid haemorrhage (SAH) & 170 & 5.1 & 42 & 5.0 & \\
\hline Unclassified & 149 & 4.4 & 38 & 4.5 & \\
\hline Unknown & 137 & 4.1 & 24 & 2.9 & \\
\hline \multicolumn{6}{|l|}{ Glasgow coma scale score, $\mathrm{n}(\%)$} \\
\hline$\geq 13$ & 2303 & 68.5 & 589 & 70.0 & 0.129 \\
\hline$<13$ (impaired consciousness) & 932 & 27.7 & 211 & 25.1 & \\
\hline Unknown & 126 & 3.8 & 41 & 4.9 & \\
\hline \multicolumn{6}{|l|}{ Incontinence, $\mathrm{n}(\%)$} \\
\hline No & 1731 & 51.5 & 422 & 50.2 & 0.553 \\
\hline Yes & 1407 & 41.9 & 355 & 42.2 & \\
\hline Unknown & 223 & 6.6 & 64 & 7.6 & \\
\hline \multicolumn{6}{|l|}{ Speech deficit, n (\%) } \\
\hline Yes & 1743 & 51.9 & 461 & 54.9 & 0.136 \\
\hline None & 1308 & 30.9 & 230 & 27.4 & \\
\hline Unknown & 580 & 17.3 & 149 & 17.7 & \\
\hline \multicolumn{6}{|l|}{ Swallow impairment, $\mathrm{n}(\%)$} \\
\hline Yes & 1197 & 35.6 & 304 & 36.2 & 0.405 \\
\hline None & 1752 & 52.1 & 448 & 53.3 & \\
\hline Unknown & 412 & 12.3 & 89 & 10.6 & \\
\hline \multicolumn{6}{|l|}{ Motor deficit, $\mathrm{n}(\%)$} \\
\hline Present & 2634 & 78.4 & 664 & 79.0 & 0.778 \\
\hline None & 568 & 16.9 & 142 & 16.9 & \\
\hline Unknown & 159 & 4.7 & 35 & 4.2 & \\
\hline
\end{tabular}

overcrowding, car ownership and proportion in social classes IV and $\mathrm{V}$ (partly skilled and unskilled) in a small area. ${ }^{17} 20$ The index was derived using 2001 census data for each lower layer super output area covered by the register. ${ }^{17} 20$ The higher the score, the more deprived. The Carstairs deprivation index has been validated and widely used in health-related studies in the UK. ${ }^{17-19}$

The diagnosis of stroke, using the WHO clinical definition, was verified by a study clinician, and patients were examined 
within $48 \mathrm{~h}$ of being notified to the SLSR where possible. We obtained the clinical details at the time of maximal impairment. These included information on motor deficit, swallowing (using the $3 \mathrm{oz}(85 \mathrm{ml})$ water swallow test), speech, visual impairments and urinary incontinence. Classification of stroke subtype (ischaemic stroke or primary intracerebral haemorrhage) was based on results from at least one of CT or MRI.

We examined a range of indicators of the processes of care after an acute stroke, and the indicators for provision of rehabilitation therapy (physiotherapy (PT) assessment within $72 \mathrm{~h}$, occupational therapy (OT) within 7 days, and speech and language therapy (SALT) within 7 days) for those with deficits for PT/OT defined as visual field defects, motor deficits and sensory deficits, and for SALT, dysarthria, dysphagia and failed swallow test. Since 2005 we also investigated other interventions, including thrombolysis within $3 \mathrm{~h}$ of symptom onset if ischaemic stroke; receipt of aspirin at any time within the 1st week of stroke or within $48 \mathrm{~h}$ if ischaemic stroke; enteral feeding (nasogastric or percutaneous endoscopic gastrostomy), after a failed swallow test result; and provision of intravenous fluids.

Follow-up data were collected by validated postal or face-to-face instruments with patients and/or their carers. Patients were assessed at 3 months and annually after stroke. We examined follow-up by a specialist or general practitioner (GP) (available data from 2002), four indicators of rehabilitation therapy provision for those with recorded deficits (PT/OT and SALT $\leq 1$ year) and 11 indicators of appropriate management of clinical risk factors (atrial fibrillation, hypertension, hypercholesterolaemia, diabetes, antiplatelet treatment for ischemic stroke).

The study was approved by the ethics committees of Guy's and St Thomas' Hospital Trust, King's College Hospital, Queen's Square, and Westminster Hospital (London).

\section{Statistical analysis}

All analyses were performed with the STATA statistical package for Windows (V.11.2, STATA Corporation, College Station, Texas, USA). Patients were divided into two groups in terms of SED status: those in the second to fifth quintiles of Carstairs scores defined as having SED and others in the first quintile as the least deprived for analysis. This is because source population of the SLSR had a higher mean Carstairs index than the general population where we have taken participants having the first tertile of Carstairs score as a reference group in the data analysis. ${ }^{19}$ We examined differences in patients' characteristics between the two SED groups, using Kruskal-Wallis method for continuous variables and the $\chi^{2}$ test for categorical variables. Multivariate adjusted logistic regression models were employed to investigate the associations of SED with short-term and longterm stroke care. We calculated ORs and their 95\% CIs for provision of acute and long-term stroke care among patients with SED. We further performed stratified data analyses for black patients and white patients and for strokes occurring in 19952000 (ie, the earlier periods) and 2001-2010 (the later periods), a period of policy-led drives to improve the quality of stroke care in the UK. To increase the statistical power, we pooled ORs for similar indicators of stroke care in ethnicity and in the stroke occurring years, and where needed, in all patients for 3 months to 5 years follow-up, according to the standard methods which we used before. ${ }^{21}$ If heterogeneity of within-indicator and between-indicator variation in those selected indicators was significant, a random effect model was used; otherwise, a fixed effect model used. We tested for an interaction on between SED and period of stroke occurrence, and patients' ethnicity using a one-sided $p$ value. ${ }^{22}$

\section{RESULTS}

From 1 January 1995 to 31 December 2010, 4212 people with first-ever stroke were registered, of whom 4202 had the Carstairs index calculated for analysis. Their mean age at onset was 70.1 years (IQR 61.6-81.1 years), 50.4\% were male and $20.4 \%$ were black patients. Table 1 shows baseline characteristics of these patients. Compared with those with the least deprived, patients with SED were more likely to be white and with stroke having occurred in the years of 2007-2010. We did not find significant differences in age, sex, living conditions, Barthel index prior to stroke, stroke subtype, Glasgow coma score, incontinence, speech deficit, swallow impairment and motor deficit between two SED groups (table 1).

\section{Acute stroke care}

Table 2 reports the specific interventions among patients after stroke. Compared with those who were the least deprived, patients with SED had significantly less chance of being admitted to hospital. There was a borderline significant association of SED with reduced swallow test, and the associations of SED with stroke unit admission, $>50 \%$ of stay on stroke unit and brain imaging were not statistically significant.

After adjustment for covariables, we observed the significant associations with hospital admission and swallow tests (table 3). A small reduction in OR was found for stroke unit admission, $>50 \%$ stay and brain imaging, but none of these reached

Table 2 Interventions in acute stroke in SLSR of 1995-2010*

\begin{tabular}{|c|c|c|c|c|c|}
\hline \multirow[b]{3}{*}{ Variable } & \multicolumn{4}{|c|}{ Socioeconomic deprivation (Carstairs score-quintile) } & \multirow[b]{3}{*}{ p Value } \\
\hline & \multicolumn{2}{|c|}{$\begin{array}{l}\text { Deprived (2nd-5th Q) } \\
\mathrm{N}=3191\end{array}$} & \multicolumn{2}{|c|}{$\begin{array}{l}\text { Least deprived (1st Q) } \\
\mathrm{N}=799\end{array}$} & \\
\hline & $\mathrm{n}$ & Per cent & $\mathrm{n}$ & Per cent & \\
\hline Hospital admission, $\mathrm{n}(\%)$ & $2783 / 3191$ & 87.8 & $721 / 799$ & 90.2 & 0.019 \\
\hline Stroke unit admission, $\mathrm{tn}(\%)$ & $1518 / 2710$ & 56.0 & $402 / 708$ & 56.8 & 0.715 \\
\hline$>50 \%$ of stay on stroke unit $\dagger$ & $1135 / 2454$ & 46.3 & $295 / 635$ & 46.5 & 0.926 \\
\hline Brain imaging, $\mathrm{n}(\%)$ & $2827 / 3044$ & 92.9 & $719 / 771$ & 93.0 & 0.710 \\
\hline Swallow test, $t$ tn (\%) & $2524 / 2768$ & 91.2 & $665 / 713$ & 93.3 & 0.074 \\
\hline
\end{tabular}




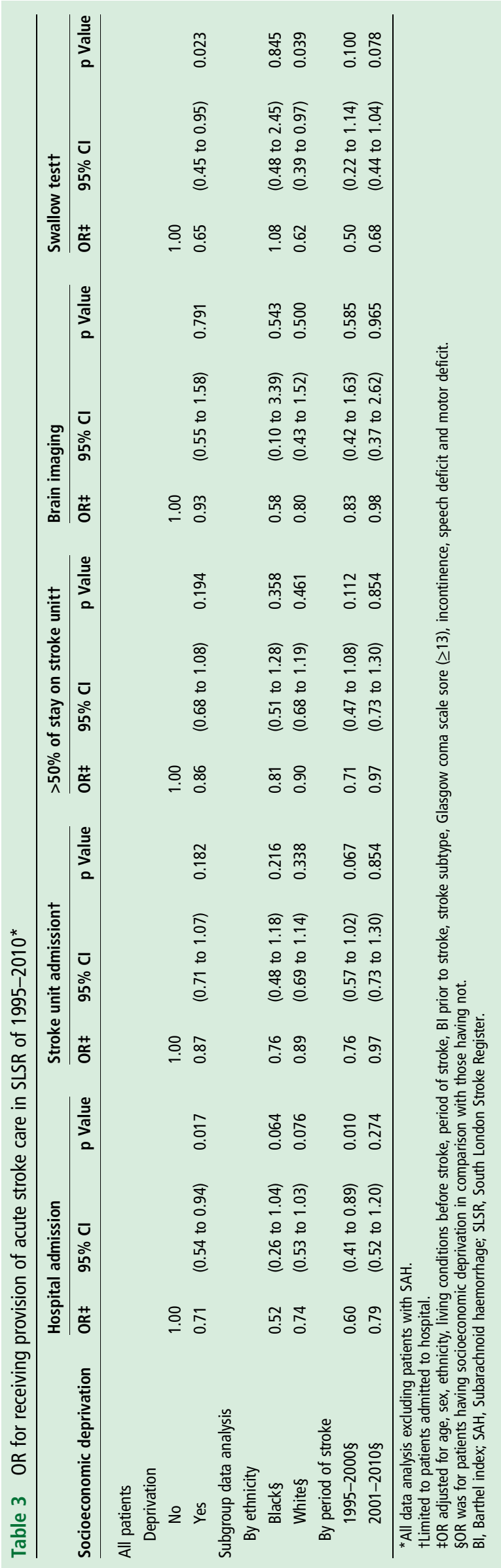

conventional statistical significance level. We pooled OR for receiving these five indicators of acute care and found a significantly reduced OR of $0.81(95 \%$ CI 0.72 to 0.92$)$ in all patients.

Stratified data analysis for ethnicity and for the period on which stroke occurred showed that there may be a stronger SED impact in black patients than in white patients (except for swallow test), and in the earlier period compared with the later period (table 3). The pooled-OR for receiving five indicators was 0.76 (0.58 to 0.99 ) in black patients with SED and 0.82 $(0.71$ to 0.96$)$ in white patients, interaction $p=0.314$, and 0.70 (0.58 to 0.84$)$ in SED patients with stroke occurring before 2001 and 0.89 (0.75 to 1.05 ) with stroke occurring since 2001, interaction $\mathrm{p}=0.030$ (figure 1 ).

Data on receipt of interventions in acute care showed no statistically significant differences among two SED groups in receiving these interventions including thrombolysis, aspirin use started at any time in acute phase and aspirin use started $48 \mathrm{~h}$ after stroke, (see online supplementary table S1). Multivariate adjusted analysis also suggested no significant association of SED with each intervention and with their combinations. However, in black patients, after pooling the ORs from the six interventions combined (thrombolysis, anytime aspirin, fed by enteral route, intravenous fluids, PT/OT and SALT), we found a statistically significant impact of SED (pooled-OR 0.48, 0.32 to $0.72)$, which was stronger that in white patients $(0.89,0.70$ to 1.13), interaction $\mathrm{p}=0.005$.

\section{Long-term stroke care from hospital discharge to 5 years follow-up}

Of the total sample, 1097 (26.0\%) died before 3 months, 2037 (48.4\%) had a 3-month assessment and 1078 (25.6\%) were lost to follow-up (declined, not traced in time, or moved away). Two thousand six hundred and sixty patients survived up to 1 year and reached the 1 year follow-up point and 1917 were then reassessed. The matched figures in years 2, 3, 4 and 5 were 2287 (1310), 1932 (1363), 1658 (1139) and 1406 (872), respectively. There were no statistically significant differences in SED between patients reassessed and not reassessed, for example, $\mathrm{p}=0.279$ at 5 year follow-up.

In the follow-up, we collected data on access to specialist/GP at 3 months and 1 year. Multivariate adjusted OR for patients with SED receiving specialist/GP was not significantly low, at 3 months 0.75 (0.52 to 1.10$)$ and at 1 year 0.79 (0.36 to 1.73 ). However, the OR at 3 months was significantly reduced among those whose stroke occurred in the later period $(0.56,0.31$ to 0.98). No interaction effect was found for ethnicity and for period in which stroke occurred.

Table 4 shows number, percentage and OR for receiving atrial fibrillation medication in eligible patients over 5 years follow-up. The association of SED with receiving less atrial fibrillation medication was found at 3 months and 5 years, but not significantly at years $2-4$. The pooled data from 3 months to years 1 , 2,3 and 5 showed an OR of 0.63 (0.48 to 0.83 ). In the stratified data analysis for ethnicity and for period on which stroke occurred, we only observed a significant OR of 0.40 (0.19 to 0.82 ) at 3 months for stroke occurring in the later period.

In data on prescribing medications for antihypertension, lowering blood cholesterol and glucose, and antiplatelet in eligible patients, we did not observe that they were significantly related to SED, except for medication for lowering blood cholesterol at 3 months (multivariate adjusted OR $0.51,0.32$ to 0.83 ) and for lowering glucose at 2 years $(0.34,0.15$ to 0.80$)$. The stratified data analysis for ethnicity and for stroke years showed no 


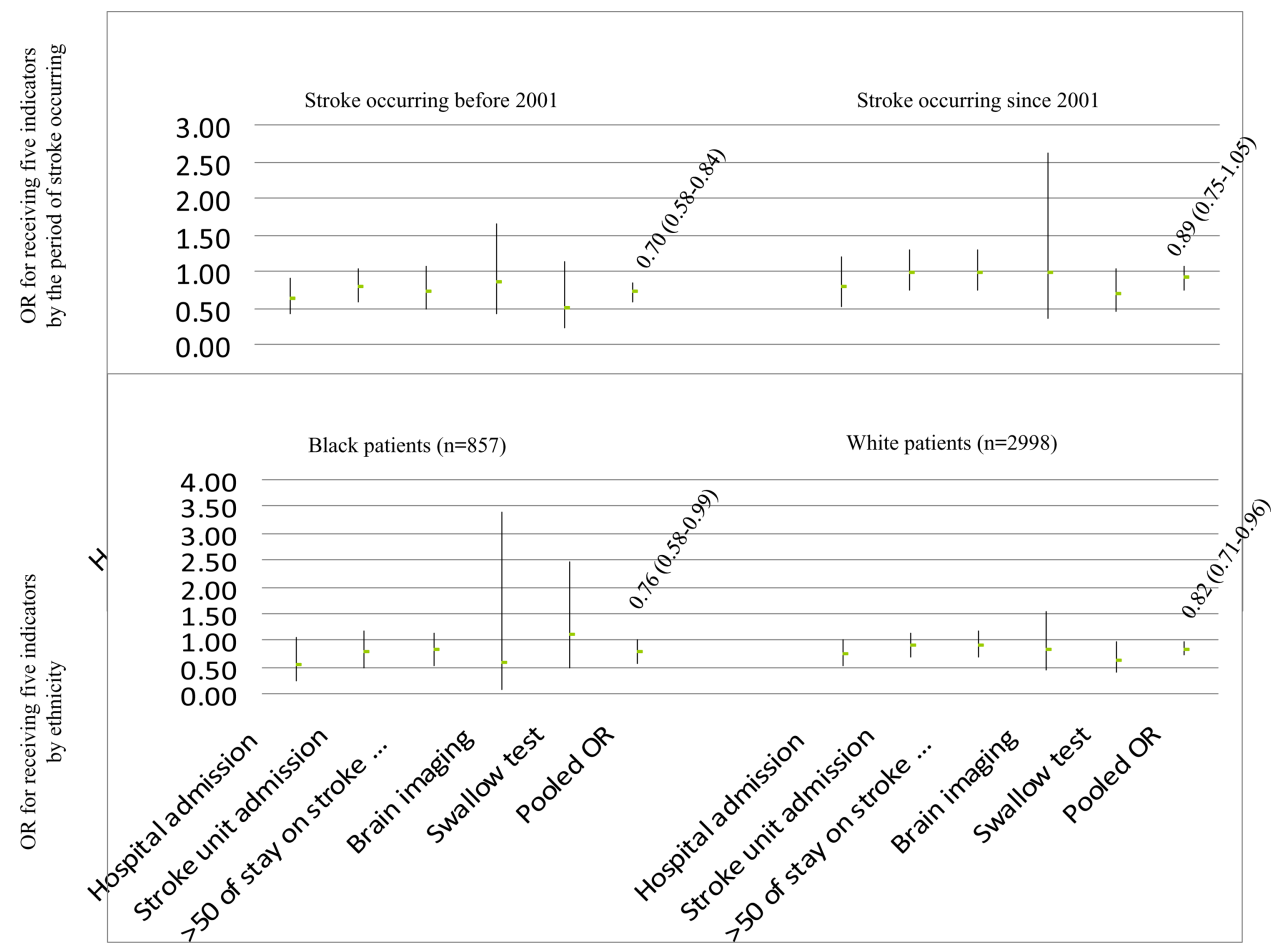

Figure 1 Combined OR for receiving five indicators of care after stroke in patients with socioeconomic deprivation (SED) by ethnicity and by the period in which stroke occurred.

significant association of SED with these medications at each time follow-up, except for lowering glucose medication (in black patients, $0.33,0.11$ to 0.95 at 3 months and $0.16,0.03$ to 0.96 at 2 years).

There was no significant association of SED with receiving PT/OT and SALT at 3 months and 1, 2, 3, 4 and 5 years after stroke. However, in the stratified data analysis we found that the significantly reduced OR was for black patients at year 3 to receive PT/OT $(0.32,0.11$ to 0.92$)$.

\section{DISCUSSION}

In this multiethnic population of patients with stroke with longterm follow-up, we found significant associations of SED with many provisions of acute and long-term stroke care. More indicators of stroke care seemed to be inversely related to SED in black patients than in white patients. There were more inequalities in stroke care in those whose stroke occurred before 2001.

To our knowledge the current study is the first to compare SED impact on stroke care between white patients and black patients who live in high-income countries. The SLSR data includes the largest proportion of black and minority ethnicity patients in the world. Although living in the same society in the UK, black people generally have lower levels of education and occupational class and are poorer than white people. These offered a unique opportunity for us to identify the association of SED with stroke care. A second strength is that our study covered a long time period, with meticulous follow-up of the patients with stroke. This allowed us to examine the impact of SED on longer-term stroke care (which has been lacking in study, before) and its secular trend, evaluating health policies. Our study has some limitations. Although the study included a large proportion of black and minority ethnicity patients, when we stratified data analysis for ethnicity the number of events was small, giving a wider CI in adjusted OR, which needs to be taken with caution when interpreting the findings. However, we employed meta-analysis techniques to pool data to further examine the association of SED with stroke care; the ethnic differences in the SED impacts were tested for significance. Thus the overall findings are robust. We had limited data on some indicators of stroke care in terms of collection from 2005, for example, receiving intervention for acute stroke, and we could not examine differences in the impact of SED between the early and the later periods. We do not have data on personal or family income for each patient, while data of educational level and occupational class include substantial missing values. We could therefore not analyse their associations with provision of stroke care. We will carry out more studies to investigate these, including breaking down Carstairs index into several components (eg, education, occupation) and further follow-up the cohort.

Previous studies reported some significant associations between SED and stroke care, mainly acute care. In Nordic countries, Langagergaard et $a l^{5}$ found that low-income patients and disabled pensioners were less likely to receive seven specific processes of care (including stroke unit care, scan, antiplatelet or anticoagulation, assessment by physiotherapist or OT) after stroke. The FINMONICA stroke register (a Finnish contribution to the World Health Organization's MONICA project (MONItoring of trends and determinants of CArdiovascular disease $)^{7}$ reported that patients from high-income groups were more likely to be treated at a university hospital, be examined by a neurology specialist and have CT or MRI. In North America, patients in the lowest-income group were less likely to receive inhospital rehabilitation treatments and waited longer for carotid endarterectomy, ${ }^{23}$ while patients from higher socioeconomic groups were more likely to receive post acute stroke rehabilitation. $^{24}$ In China, patients with stroke with lower income and those without medical insurance were less likely to receive antithrombotic therapy. ${ }^{25}$ 
Table 4 Associations between socioeconomic deprivation and access to atrial fibrillation medical follow-up in SLSR of 1995-2010

\begin{tabular}{|c|c|c|c|c|c|c|c|c|}
\hline \multirow[b]{3}{*}{ Socioeconomic deprivation } & \multicolumn{8}{|c|}{ Atrial fibrillation medication* } \\
\hline & \multicolumn{2}{|c|}{ Yes } & \multicolumn{2}{|l|}{ No } & \multirow[b]{2}{*}{ p Value } & \multicolumn{3}{|c|}{ Multivariate adjusted } \\
\hline & $\mathbf{n}$ & Per cent & n & Per cent & & ORt & $95 \% \mathrm{Cl}$ & p Value \\
\hline \multicolumn{9}{|l|}{ At 3 months } \\
\hline \multicolumn{9}{|l|}{ Deprivation } \\
\hline No & 45 & 35.2 & 47 & 18.5 & & & & \\
\hline Yes & 83 & 64.8 & 207 & 81.5 & 0.000 & 0.46 & 0.27 to 0.79 & 0.005 \\
\hline \multicolumn{9}{|l|}{ At 1 year } \\
\hline \multicolumn{9}{|l|}{ Deprivation } \\
\hline No & 37 & 30.8 & 53 & 22.5 & & & & \\
\hline Yes & 83 & 30.7 & 183 & 77.5 & 0.086 & 0.75 & 0.42 to 1.31 & 0.311 \\
\hline \multicolumn{9}{|l|}{ At 2 years } \\
\hline \multicolumn{9}{|l|}{ Deprivation } \\
\hline No & 22 & 25.3 & 37 & 20.6 & & & & \\
\hline Yes & 65 & 74.7 & 143 & 79.4 & 0.382 & 0.93 & 0.45 to 1.94 & 0.856 \\
\hline \multicolumn{9}{|l|}{ At 3 years } \\
\hline \multicolumn{9}{|l|}{ Deprivation } \\
\hline No & 27 & 29.0 & 33 & 22.3 & & & & \\
\hline Yes & 66 & 71.0 & 115 & 77.7 & 0.239 & 0.69 & 0.33 to 1.43 & 0.316 \\
\hline \multicolumn{9}{|l|}{ At 4 years } \\
\hline \multicolumn{9}{|l|}{ Deprivation } \\
\hline No & 19 & 25.0 & 33 & 23.7 & & & & \\
\hline Yes & 57 & 75.0 & 106 & 76.3 & 0.837 & 0.79 & 0.36 to 1.72 & 0.554 \\
\hline \multicolumn{9}{|l|}{ At 5 years } \\
\hline \multicolumn{9}{|l|}{ Deprivation } \\
\hline No & 21 & 32.8 & 19 & 16.7 & & & & \\
\hline Yes & 43 & 67.2 & 95 & 83.3 & 0.013 & 0.39 & 0.17 to 0.88 & 0.024 \\
\hline
\end{tabular}

In the current study, we found that there were significant associations between SED and multiple components of acute and long-term stroke care. The most important finding is that there was a stronger impact of SED on provision of stroke care in black patients than their white counterparts. Previous studies $^{26}$ mainly investigated ethnic differences in stroke care, showing that black patients with stroke received fewer evidence-based care processes. The current study has identified that within black patients SED was associated with poor stroke care, and the association may be stronger than in white patients. This suggests that addressing healthcare inequality in stroke in black patients may be behind that in whites, and strategies for reducing health inequality should target on this population.

Our study has shown that the impact of SED appears to have attenuated with time, which may be associated with changes in health policies, organisation of stroke services and the application of new scientific evidence into clinical practice. It has probably reflected increased efforts in the UK to improve the quality of stroke care through a raft of policy initiatives including the National Stroke Strategy ${ }^{10}$ and a rolling national programme of audit of clinical guideline implementation. ${ }^{11} 27$ This is a good achievement in public health. However, significantly reduced ORs for specialist/GP follow-up and for atrial fibrillation medication were observed in the later periods, and black patients appeared to still have healthcare inequality in stroke. Our findings could help improve making of health policies.
We did not observe significant associations of SED with other indicators of stroke care, for example, antihypertensive and antiplatelet medication, SALT, PT/OT (except in black patients). This may suggest that the government has dealt with health inequality in stroke care on these aspects or these are more easily established as routine care for all patients with stroke. An Austrian study also suggested no socioeconomic differences in the administration of thrombolysis, or the rate of prescribing secondary prevention drugs. ${ }^{8}$ Equal access to stroke unit care and an apparent equity in thrombolysis provision among all socioeconomic groups was reported in patients from three Scottish hospitals with universal access to care. ${ }^{9}$ However, the SLSR data showed that patients with SED had less chance of being given medication for atrial fibrillation in acute and longterm phases. It is an interesting finding in the current study. This would have an important implication and may help explain a high level of mortality in patients with stroke with SED. We need to carry out a further study to investigate its reasons and reduce inequality in secondary stroke prevention. Nevertheless, our study is of timely importance for clinicians and health policy makers for reducing healthcare inequality and improving the prognosis of stroke.

Variations in the findings of the association between SED and stroke care provision may reflect different healthcare systems among these countries and improvement on reducing healthcare inequality in stroke over time. It may also be due to different indicators of stroke care and duration of the 
follow-up. In this long-term follow-up study, using a comprehensive measurement of SED, ${ }^{19}{ }^{20}$ we found an overall significant association with many indicators. Recently having analysed data from Hospital Episode Statistics in England, Lazzarino et $a l^{28}$ also reported that SED (measured using the Carstairs index as well) was related to less chance of being selected for emergency admission for stroke and for a brain scan on the same day of admission in patients scanned at any time in the same hospital. Our data further showed that the impact of SED was greater in black patients. All these suggest that stroke healthcare inequality still remains in England, particularly in an ethnic population. Our study may help explain why patients with SED had a poorer prognosis of stroke than patients who were not in SED. ${ }^{2} 6$

\section{Conclusions}

This study has shown an overall significant association between SED and reduced access to acute and long-term stroke care in a multiethnic population of patients with stroke in England. Inequalities in stroke care provision were more obviously observed in black patients than in white patients. There were improvements in some indicators over time. Reducing the poverty in black and other minority populations may help reduce health in equality in stroke nationally and internationally. Further investigation is required to understand how these improvements were achieved to address other aspects of stroke care where inequalities in access remain.

Contributors Study concept and design: RC, CDAW. Data collection and supervision: CDAW, CM, AGR. Analysis and interpretation of data: RC, SLC, CDAW. Drafting of the manuscript: RC, CM. Critical revision of the manuscript for important intellectual content: CDAW, AGR, CM, SLC, RC. Obtained funding: CDAW, AGR, CM. Administrative, technical and material support: CDAW, SLC, RC, CM. CDAW is the guarantor of this paper.

Funding The study was funded by Guy's and St Thomas' Hospital Charity, The Stroke Association, Department of Health (Health Quality Improvement Programmer grant), and National Institute for Health Research Programme Grant (RP-PG-0407-10184), United Kingdom. The authors acknowledge financial support from the Department of Health via the National Institute for Health Research (NIHR) Biomedical Research Centre and the Programme Grant award to Guy's and St Thomas' NHS Foundation Trust in partnership with King's College London. Professor Charles DA Wolfe is a senior investigator for the NIHR.

\section{Competing interests None.}

Patient consent Obtained.

Ethical approval The study was approved by the ethics committees of Guy's and St Thomas' Hospital Trust, King's College Hospital, Queen's Square, and Westminster Hospital (London).

Provenance and peer review Not commissioned; externally peer reviewed.

\section{REFERENCES}

1 Lozano R, Naghavi M, Foreman K, et al. Global and regional mortality from 235 causes of death for 20 age groups in 1990 and 2010: a systematic analysis for the Global Burden of Disease Study 2010. Lancet 2012;380:2095-128.

2 Cox AM, McKevitt C, Rudd AG, et al. Socioeconomic status and stroke. Lancet Neurol 2006;5:181-8
3 Steenland K, Hu S, Walker J. All-cause and cause-specific mortality by socioeconomic status among employed persons in 27 US states, 1984-1997. Am J Public Health 2004;94:1037-42.

4 Li C, Hedblad B, Rosvall M, et al. Stroke incidence, recurrence, and case-fatality in relation to socioeconomic position: a population-based study of middle-aged Swedish men and women. Stroke 2008;39:2191-6.

5 Langagergaard V, Palnum KH, Mehnert $F$, et al. Socioeconomic differences in quality of care and clinical outcome after stroke: a nationwide population-based study. Stroke 2011;42:2896-902.

6 Addo J, Ayerbe L, Mohan KM, et al. Socioeconomic status and stroke: an updated review. Stroke 2012;43:1186-91.

7 Jakovljevic D, Sarti C, Sivenius J, et al. Socioeconomic status and ischemic stroke: the FINMONICA Stroke Register. Stroke 2001;32:1492-8.

8 Arrich J, Mullner M, Lalouschek W, et al. Influence of socioeconomic status and gender on stroke treatment and diagnostics. Stroke 2008;39:2066-72.

9 Kerr GD, Higgins $P$, Walters $M$, et al. Socioeconomic status and transient ischaemic attack/stroke: a prospective observational study. Cerebrovasc Dis 2011; 31:130-7.

10 Department of Health. National stroke strategy. London: Department of Health, 2007.

11 Royal College of Physicians (Intercollegiate Stroke Working Party). National clinical guidelines for stroke. 3rd edn. London: Royal College of Physicians, 2008.

12 Wolfe CD, Crichton SL, Heuschmann PU, et al. Estimates of outcomes up to ten years after stroke: analysis from the prospective South London Stroke Register. PLoS Med 2011:8:e1001033.

13 Addo J, Bhalla A, Crichton S, et al. Provision of acute stroke care and associated factors in a multiethnic population: prospective study with the South London Stroke Register. BMJ 2011;342:d744.

14 Stewart JA, Dundas R, Howard RS, et al. Ethnic differences in incidence of stroke: prospective study with stroke register. BMJ 1999:318:967-71.

15 Tilling K, Sterne JA, Wolfe CD. Estimation of the incidence of stroke using a capture-recapture model including covariates. Int J Epidemiol 2001;30:1351-9.

16 McKevitt C, Coshall C, Tilling K, et al. Are there inequalities in the provision of stroke care? Analysis of an inner-city stroke register. Stroke 2005:36:315-20.

17 Carstairs V, Morris R. Deprivation and health in Scotland. Aberdeen: Aberdeen University Press, 1991

18 Wilson KC, Chen R, Taylor S, et al. Socio-economic deprivation and the prevalence and prediction of depression in older community residents. The MRC-ALPHA Study. Br J Psychiatry 1999:175:549-53.

19 Chen R, Tunstall-Pedoe H. Socioeconomic deprivation and waist circumference in men and women: the Scottish MONICA surveys 1989-1995. Eur J Epidemiol 2005;20:141-7

20 Carstairs V, Morris R. Deprivation: explaining differences in mortality between Scotland and England and Wales. BMJ 1989;299:886-9.

21 Hemingway $H$, Philipson $P$, Chen $R$, et al. Evaluating the quality of research into a single prognostic biomarker: a systematic review and meta-analysis of 83 studies of C-reactive protein in stable coronary artery disease. PLoS Med 2010;7:e1000286.

22 Altman DG, Bland JM. Interaction revisited: the difference between two estimates. BMJ 2003:326:219.

23 Kapral MK, Wang H, Mamdani M, et al. Effect of socioeconomic status on treatment and mortality after stroke. Stroke 2002;33:268-73.

24 Sandel ME, Wang $H$, Terdiman J, et al. Disparities in stroke rehabilitation: results of a study in an integrated health system in northern California. PM R 2009;1:29-40.

25 Wang YL, Wu D, Nguyen-Huynh MN, et al. Antithrombotic management of ischaemic stroke and transient ischaemic attack in China: a consecutive cross-sectional survey. Clin Exp Pharmacol Physiol 2010;37:775-81.

26 Schwamm LH, Reeves MJ, Pan W, et al. Race/ethnicity, quality of care, and outcomes in ischemic stroke. Circulation 2010;121:1492-501.

27 Irwin $\mathrm{P}$, Hoffman A, Lowe $\mathrm{D}$, et al. Improving clinical practice in stroke through audit: results of three rounds of National Stroke Audit. J Eval Clin Pract 2005:11:306-14

28 Lazzarino Al, Palmer W, Bottle A, et al. Inequalities in stroke patients' management in English public hospitals: a survey on 200,000 patients. PLOS ONE 2011;6: e17219. 